\title{
International Association for Trauma Surgery and Intensive Care (IATSIC) Presidential Address: Improving Trauma Care Globally: How is IATSIC Doing?
}

\author{
Charles Mock ${ }^{1,2}$
}

Published online: 23 August 2016

(C) Société Internationale de Chirurgie 2016

\begin{abstract}
Abstarct IATSIC is the foremost professional society addressing trauma care globally. How is it doing in meeting the needs of most injured patients? The vast majority ( $65 \%)$ of trauma deaths occur in the poorer half of the world (low-income and lower-middle-income countries), where injury rates are the highest. IATSIC has accomplished a tremendous amount and has much to be proud of. However, most of its work thus far has been concentrated in the wealthier half of the world (upper-middle-income and high-income countries). For example, most of the speakers on IATSIC's biannual program are from upper-middle-income and high-income countries and most of IATSIC's courses are conducted in these countries. IATSIC's trauma systems publications have been utilized in countries at all economic levels (including many low-income and lower middle-income countries), but much more needs to be done. IATSIC'S foundation is its membership. Only $5 \%$ of our members come from the poorer half of the world. In order to make more of a difference for the majority of injured people in the world, IATSIC needs to expand its reach to where they live. Major priorities are: (1) increase representation from low- and lower middle-income countries in our scientific program; (2) disseminate of our courses more widely; (3) increase utilization of our trauma system publications, especially for higher yield activities, such as longitudinal monitoring of trauma systems, implementation in health policy, and developing curricula for trauma care in medical schools and in post-graduate training; and (4) especially, recruit new members from low- and lower-middle-income countries.
\end{abstract}

What type of care do the majority of injured people receive?

I am very honored to have served as IATSIC President for the past two years (2013-2015). IATSIC is the foremost professional society addressing trauma care globally. So, I would like to use this talk to ask, how we are doing in this role. What are we doing well, and should keep doing; and

\section{Charles Mock}

cmock@uw.edu

1 Department of Surgery, University of Washington, Seattle, WA, USA

2 Harborview Injury Prevention and Research Center, Harborview Medical Center, 325 Ninth Avenue, Box 359960, Seattle, WA 98104, USA what are the areas that need improvement? I would especially like to ask how we are doing in reaching the majority of injured people in the world.

Let me start by asking who are the majority of injured people? What type of circumstances do they find themselves in? What type of care do they receive?

- Do they receive the type of care common in wealthy countries, with advanced life support equipped ambulances reaching the scene within minutes and with wellequipped operating rooms and intensive care units?

- Do they receive the type of care common in middleincome countries, some of which is very good; and some of which is challenging, especially in busy public hospitals and rural areas.

- Or, do they receive the type of care common in the poorest countries, with no emergency medical services 
Table 1 Population, injury death rates, and total number of injury deaths by economic status. Source of data: World Bank; World Health Organization Global Health Estimates

\begin{tabular}{|c|c|c|c|c|}
\hline Category of country & Low-income & $\begin{array}{l}\text { Lower-middle- } \\
\text { income }\end{array}$ & Upper-middle-income & High-income \\
\hline GNI per capita & $<\$ 1046$ & $\$ 1046-\$ 4125$ & $\$ 4126-\$ 12,735$ & $>\$ 12,736$ \\
\hline Examples & $\begin{array}{l}\text { Most of sub-Saharan } \\
\text { Africa }\end{array}$ & $\begin{array}{l}\text { India and } \\
\text { southern Asia }\end{array}$ & $\begin{array}{l}\text { China, South Africa, } \\
\text { most of Latin America }\end{array}$ & $\begin{array}{l}\text { Western Europe, } \\
\text { North America }\end{array}$ \\
\hline $\begin{array}{l}\text { Mean total health expenditure } \\
\text { per capita }\end{array}$ & $\$ 37$ & $\$ 89$ & $\$ 487$ & $\$ 4543$ \\
\hline $\begin{array}{l}\text { Mean government health } \\
\text { expenditure per capita }\end{array}$ & $\$ 14$ & $\$ 32$ & $\$ 274$ & $\$ 2812$ \\
\hline Population & 0.8 billion & 2.5 billion & 2.4 billion & 1.3 billion \\
\hline $\begin{array}{l}\text { Injury mortality rate } \\
\text { (per } 100,000 \text { annually) }\end{array}$ & 89 & 87 & 61 & 58 \\
\hline $\begin{array}{l}\text { Total number of injury } \\
\text { deaths annually }\end{array}$ & 751,000 & $2,169,000$ & $1,478,000$ & 747,000 \\
\hline
\end{tabular}

Two thirds of injury deaths occur in the poorer half of humanity who live in low- and lower-middle-income countries. GNI: Annual gross national income per capita in US\$, using World Bank Atlas method, 2014. Health expenditures expressed as mean for all countries in a given category, per capita per year in US\$

at the scene, but rather whatever assistance is delivered by their relatives or bystanders; and where care in rural areas often needs to be delivered in very basic clinics with limited opportunity for urgent referral; and where, if people do reach hospitals, they are cared for in operating rooms with the most minimal of equipment.

\section{In which of these scenarios do the greatest numbers of injured people find themselves?}

To answer that question, let's look at the distribution of the world's people by the economic status of the countries where they live. The World Bank categorizes countries based on their gross national income (GNI) per capita per year (Table 1) [1]. Examples of countries or regions in these categories include: Europe and North America (highincome); Republic of South Africa, China, and most of Latin America (upper-middle-income); India and most of Southern Asia (lower-middle-income); and most of subSaharan Africa (low-income). Most of the world's people live in middle-income countries, with smaller numbers (approximately a billion each) in the very poor (low-income) and the very rich (high-income) countries.

Of course, these categories are somewhat artificial and nothing magic happens when a country crosses one of these economic thresholds. But, still, this categorization is closely related to many measures of human well-being, such as literacy, malnutrition, life expectancy, infant mortality rate, and rates of death from trauma, which climb steadily as income levels decrease, from 58 deaths/100,000/year in high-income countries to 89 deaths/100,000/year in lowincome countries [2].

Hence, where are most trauma deaths occurring, can be easily seen by the injury death rate times the population (Table 1). As you might expect, most deaths occur in the more highly populated middle-income countries, but especially in the lower-middle group, with over 2 million out of the annual 5 million trauma deaths. Lesser numbers of trauma deaths occur in the poorest and wealthiest countries. But once again, it should be emphasized that the rates are much higher in the low-income countries, so, although their population is lower than the wealthiest countries, the number of trauma deaths is higher. Altogether, the poorer half of humanity (low-income and lowermiddle-income countries) accounts for the vast majority (two thirds) of all trauma deaths. So, although every part of the world has a large health burden from trauma, the lion's share of this is in the poorest countries. These are countries where health resources are very limited. For example, many African countries have only $\$ 10-\$ 20$ per capita per year to spend on health, in comparison with hundreds in middle-income countries, and thousands in high-income countries. So, if we are looking to improve trauma care, we need to find solutions that are affordable within these restrictions. And one might think, how can a country whose government only has \$10-20 per person per year to spend on all of health care make any improvements in trauma care at all?

Despite these barriers, there are many people (trauma surgeons and other clinicians) working every day in very impoverished, very difficult circumstances, often coming up with very innovative solutions to the problems they 
Table 2 Distribution of IATSIC activities by economic status of countries involved

\begin{tabular}{lcccc}
\hline Category of country & Low-income & Lower-middle-income & Upper-middle-income & High-income \\
\hline County of panel presenters $^{\mathrm{a}}$ & 0 & 3 & 9 & 34 \\
Country of abstract presenters $^{\mathrm{a}}$ & 0 & 9 & 5 & 52 \\
Countries with DSTC courses $_{\text {Ongoing NTMC program }}$ & 0 & 2 & 5 & 22 \\
Utilization of IATSIC/WHO trauma system guidelines & 14 & 2 & 0 & 0 \\
\end{tabular}

DSTC, Definitive Surgical Trauma Care course. Countries noted above range from having had single courses to having ongoing, established national programs; NTMC, National Trauma Management Course

a At World Congress of Surgery, Bangkok, 2015

face. So, my main question is: How is IATSIC doing in adding to these efforts, at aiding our colleagues working in such locations, and at improving care for the injured in the circumstances where most injuries occur?

\section{IATSIC activities: scientific program}

IATSIC works in three main ways: our biannual scientific program, our courses, and our guidelines and other publications. One of our most prominent activities is our biannual program. Our constitution states: "The object of the association shall be to provide an international forum for exchanging information"... [3].

How is our scientific program doing at addressing the needs of the majority of trauma patients globally? This can be looked at in several ways: One is the topics discussed and another is where are the presenters from. For the 2015 World Congress of Surgery in Bangkok, both our invited panels and our accepted abstracts (oral and poster) featured presenters who were predominantly from high-income countries (Table 2). There was moderate representation from middle-income countries, and none from low-income countries. Based on the simple fact of where presenters are from, we can conclude that the role of the IATSIC program in addressing the majority of trauma patients globally is: "not bad, but we could do better" (many of the questions I ask will have that answer).

In summary for our program, most speakers are from high-income countries, not bad for upper-middle-income countries, but very few speakers from the half of the world where most injuries occur (lower-middle-income and lowincome countries). Of course, some of the talks by highincome country presenters might cover material relevant to all locations and some might even focus on lower-income situations. But, nonetheless, the country of origin of the presenter is one metric of how well our program is addressing the needs of trauma care globally. By the way, when I go into our other activities, I hope that no one takes offense. I am stating the facts as objectively as I can and do not intend to point fingers of blame, but instead to look for opportunities for improvement. However, if anyone might take offense at what I say, please note that I am starting with the scientific program. I have been the program chair for the past 4 years (and I am one of the high-income presenters), so if there is fault to be found on this, the blame is on me more than anyone else.

\section{IATSIC activities: courses}

Equal in prominence to our biannual meeting are our courses. In between the biannual congresses, the courses are the embodiment of IATSIC. There are two main courses we run are: Definitive Surgical Trauma Care (DSTC) and National Trauma Management Course (NTMC). DSTC was the first course developed that emphasized surgical technique in trauma, above and beyond the basic resuscitation and work-up which had been the main topic that trauma courses had previously addressed. DSTC is especially oriented for general surgeons who see only a little trauma and who are less than optimally experienced with operative management, especially for difficult situations such as retroperitoneal or vascular injuries.

IATSIC runs 30-40 DSTC courses per year, with around 400 courses having been run since the beginning. DSTC has been conducted in 29 countries. As with our scientific program, the distribution by economic level of countries is good, but with opportunities for expansion (Table 2). A lot of courses in high-income countries; fairly good number of courses in upper-middle-income countries, especially Latin America and South Africa; two lower-middle-income countries-Yemen (courses in the past) and development of an ongoing national program in the Philippines; but with no courses yet in low-income countries. So, there is a lot of room still for expansion. And I do not say that lightly, as I know that the setting up the animal lab, with veterinary ethical certification (which is necessary so that the DSTC program is not prejudiced in other countries), is very time consuming and, although possible, likely to be more difficult in lower-income sites. 
IATSICs other major course is NTMC: a course on initial management and work-up of trauma patients in the emergency department setting, oriented for all doctors. This has been primarily run in two countries (India and Sri Lanka), being franchised to national bodies (Academy of Traumatology of India and Sri Lankan College of Surgeons). Over the past 10 years, 80 courses have been run, with around 7000 doctors trained. All of this activity has been in lower-middle-income countries. There have also been one off courses in Kazakhstan and several African countries.

There is a major need to expand the reach of NTMC. For most of the world, there is a dearth of availability of such trauma short courses. As just one piece of evidence for that, IATSIC and WHO evaluated trauma care resources in 100 health care facilities in four countries (Ghana, India, Mexico, Vietnam). One item evaluated was whether front line trauma care providers (doctors working in the emergency departments and surgeons taking trauma call) had ever taken a continuing medical education course on trauma care, such as NTMC and Advanced Trauma Life Support. These courses or similar locally developed courses were available in all four countries. However, very few doctors had taken them. No one working in rural clinics had taken such courses, even though the rural clinics in the study were selected to be those that received many severely injured people due to their locations on busy roads, far from hospitals, and in locations with no or only rudimentary ambulance services. Smaller hospitals had far less than $50 \%$ of doctors with such training, in all countries. And even bigger hospitals, usually the major trauma hospital in their area, mostly less than $50 \%$ of doctors that you would have expected to have such training had it. Only the uppermiddle-income site, Mexico, had rates above $50 \%$ (but still far below $100 \%$ ) [4]. Thus, there is a huge unmet need for such basic trauma care courses globally and NTMC is perfectly designed to meet that need. A major emphasis of IATSIC should be to promote this course more globally.

\section{IATSIC activities: trauma system publications}

IATSIC has been involved with three related publications: Guidelines for Essential Trauma Care, Guidelines for Trauma Quality Improvement Programmes, and Prehospital Trauma Care Systems [5-7]. The first two were copublished by IATSIC and WHO. The latter was a WHO publication, but with considerable input from IATSIC members. All three publications define minimum, effective, essential trauma care services that all injured people should be able to receive, even in the poorest locations. The publications also delineate the human resources (skills, staffing, training), physical resources (equipment, supplies), and administrative mechanisms needed to assure these minimum level of services.

Guidelines for Essential Trauma Care is similar in concept to the American College of Surgeon's Resources for Optimal Care of the Injured Patient [8], giving recommendations on the resources needed for trauma care at different size hospitals. However, it is oriented for the realities of countries that have hundreds of dollars or even just \$10-20 per capita to spend on health, compared with thousands of dollars in high-income countries. The Guidelines for Essential Trauma Care has been translated into multiple languages (Arabic, English, French, Spanish, Russia, Vietnamese). Prehospital Trauma Care Systems gives guidance to country governments on how to implement and expand basic ambulance services. And when these are too costly or not practical, it gives guidance on how to make better use of existing first responders (e.g., commercial drivers, police, fire service, Red Cross and Red Crescent volunteers). Guidelines for Trauma Quality Improvement Programmes gives guidance on simple, feasible methods, such as getting more out of existing Morbidity and Mortality (M\&M) meetings and especially how to use whatever basic quality improvement activities exist to take corrective action and actually fix problems that have been identified.

These three publications involved a tremendous amount of work by many people (each publication with over 50 contributors). How do we know if these are really of any use? How do we know if people are utilizing them and, if so, where and how? To answer that question, we undertook a systematic review of what is in the literature or elsewhere on the web that references these publications. This used established and rigorous methods and searched 19 databases in 7 languages (Arabic, Chinese, English, French, Russian, Spanish, Portuguese). Articles that referenced the IATSIC-WHO guidelines were identified and were categorized as to whether or not they merely referenced one of the guidelines or whether they described some sort of implementation or utilization of the guidelines [9].

There were 140 reports of utilization from 51 countries. Reports of utilization included needs assessments (44\% of reports of utilization); use in developing educational programs (14\%); stakeholder endorsement (28\%); and implementation in policy $(14 \%)$. The articles that reported utilization came from a variety of sources. But the majority (55\%) were fairly significant in that they were from peer reviewed, PubMed referenced journals. There were an even larger number of articles (564) that referenced the publication, either by way of advocating for their recommendations or just referencing them to back up a fact or statement, but which did not report on use of the guidelines [9]. I would like to give an example of each type of utilization. 
Needs assessments evaluated the status of resources for trauma care for networks of hospitals, compared with the criteria in the publications, especially the Guidelines for Essential Trauma Care. These reports called attention to low-cost deficiencies that could be easily improved upon. However, very few used the guidelines in a longitudinal fashion, reporting on changes over time or in response to interventions.

Multiple publications reported on the use of all three of the guidelines in designing educational programs, such as one publication that reported on the use of the Prehospital Trauma Care Systems in developing curriculum for Red Cross volunteers in Lebanon [10]. In addition to usage in individual countries, the guidelines have been used to develop two self-sustaining courses reaching large regional audiences. The Guidelines for Trauma Quality Improvement Programmes has been translated into Spanish and Portuguese by the Pan-American Trauma Society and used to develop a course oriented for Latin America, conducted regularly as part of their annual congress [11]. All three publications have been used by the West African College of Surgeons to develop a course on trauma system planning, oriented for Africa and conducted regularly as part of their annual congress and with attendees from most of the 17 West African countries. Hence, there has been a lot of utilization of these publications in short continuing education courses. However, we only found one example of them being used in defining core competencies for residency training [12] and none in developing curricula for schools of medicine or nursing, which should be a future priority for implementation.
A wide variety of national and regional professional societies (e.g., African Federation of Emergency Medicine, Ghana Medical Association, Pan-American Trauma Society, Sri Lankan College of Surgeons) have endorsed the guidelines and called for their implementation in their country or region. Most of these were in the form of short statements $[9,13]$. Some were more detailed, such as a 300 page book by the National Academy of Medicine of Argentina, which used the Guidelines for Essential Trauma Care to create a set of recommendations, oriented for the circumstances of that country [14].

The ultimate use of the publications is when they are implemented in law or health policy, such as when the Prehospital Trauma Care Systems was used in the development of Colombia's first nationwide emergency medical services legislation $[9,13]$. Such policy implementation was the least common method of usage, and this is a future direction that needs to be emphasized more.

In summary, there has been a wide, global utilization of the IATSIC-WHO trauma system publications (Fig. 1). This has also been the IATSIC activity with the most reach in the poorer half of the world. Reports of utilization came from 14 low-income countries (41\% of all low-income countries) and 15 lower-middle-income countries (32\%). Interestingly, although these publications were developed specifically for low- and middle-income countries, there has been some usage in high-income countries (e.g., France, Poland, and Scotland in the UK). So, there has been a lot of accomplishments and a lot of utilization, but there is still a long way to go. Most countries have not reported using the guidelines. Some areas have used them

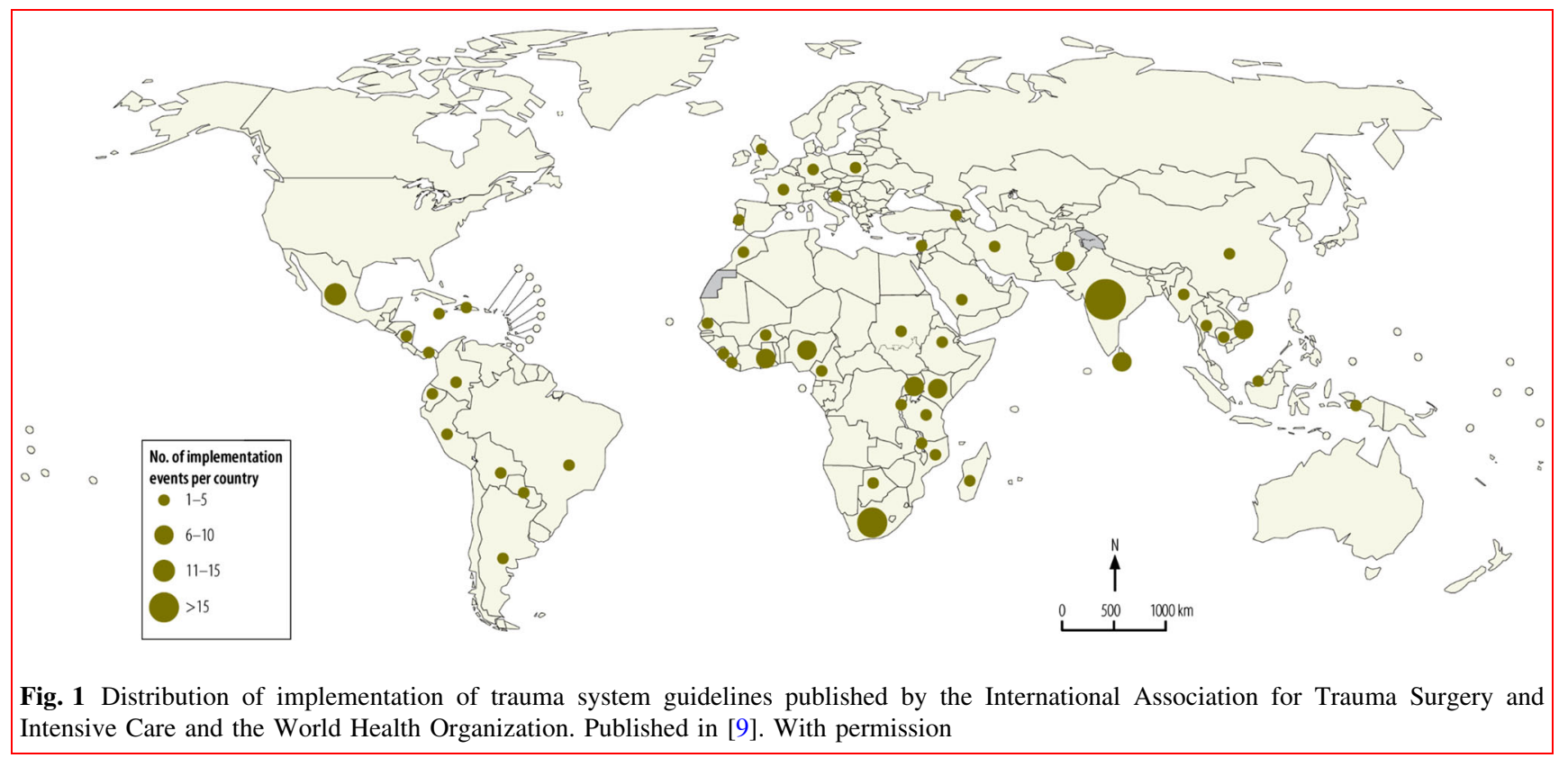


Table 3 Distribution of IATSIC membership by country

\begin{tabular}{|c|c|c|c|c|}
\hline Category of country & $\begin{array}{l}\text { Low- } \\
\text { income }\end{array}$ & $\begin{array}{l}\text { Lower-middle- } \\
\text { income }\end{array}$ & $\begin{array}{l}\text { Upper-middle- } \\
\text { income }\end{array}$ & High-income \\
\hline $\begin{array}{l}\text { IATSIC membership (number of members } \\
\text { by category of country) }\end{array}$ & 0 & 18 & 51 & 296 \\
\hline $\begin{array}{l}\text { Examples of countries with high numbers } \\
\text { of members }\end{array}$ & & $\begin{array}{l}\text { Nigeria: } 5 \\
\text { India: } 4\end{array}$ & $\begin{array}{l}\text { Latin America: } 23 \\
\text { Brazil: } 13 \\
\text { South Africa: } 15\end{array}$ & $\begin{array}{l}\text { Western Europe: } 95 \\
\quad \text { (16 countries) } \\
\text { Switzerland: } 15 \\
\text { USA: } 89 \\
\text { Australia \& NZ: } 31 \\
\text { Japan: } 29\end{array}$ \\
\hline
\end{tabular}

very minimally, such as North Africa and the Middle East. Most reports are in English, even those from Latin America or Francophone West Africa. And, once again, although there are some good examples of policy implementation, this category had the smallest level of utilization.

\section{IATSIC membership}

IATSIC is its membership. All of the above activities depend on our members. How does our membership reflect the needs of trauma patients globally? We have great representation across the high-income world (Table 3). We have reasonable representation from upper-middle-income countries, especially Latin America and South Africa. While we do have members from Hong Kong and Taiwan, we have no members from the world's biggest country, the People's Republic of China. Almost certainly there are interesting, innovative things going on in trauma care there and IATSIC and the trauma care community in China would both benefit from mutual exchange of information. We have small representation from lower-middle-income countries, namely India and some of the African countries that have had economic progress recently. But out of the 31 countries currently listed as low-income, the bottom billion, the poorest part of humanity, where the rates of trauma death are the highest and where trauma patients would stand to benefit the most from IATSICs involvement, we do not have single member. These include a few countries in Asia (Afghanistan, Cambodia, Nepal), Haiti in the Western Hemisphere, and otherwise almost all of the others are sub-Saharan African countries.

Taken altogether, only $5 \%$ of IATSIC members come from the countries where the vast majority $(65 \%)$ of trauma occurs (low-income and lower-middle-income). If we are going to meaningfully improve the care of most trauma patients in the world, we need much more engagement with the surgeons caring for these patients.

\section{Conclusions}

IATSIC has accomplished a tremendous amount and has much to be proud of. It has substantial reach in high-income countries and reasonable reach in upper-middle-income countries. However, it needs to expand its reach in the poorer half of the world (low- and lower-middle-income countries, where $65 \%$ of all injuries occur). Major priorities to accomplish this include:

(1) Increase representation from low- and lower-middleincome countries on our scientific program. Although speakers from high-income countries are discussing information useful for surgeons from any environment, if we are going to meaningfully address the needs of most trauma patients in the world, we need more involvement on our program of surgeons caring for these patients.

(2) Greater dissemination of our courses, especially NTMC.

(3) Increase utilization of our trauma system publications, especially for higher yield activities, such as longitudinal monitoring of trauma system capabilities, developing curricula for trauma care in schools of medicine and nursing and post-graduate training (in addition to the in-service type courses for which the publications have already been used), and implementation in health policy and law.

(4) Above all else, greater recruitment of new members from low- and lower-middle-income countries.

Thank you for the privilege of having been able to serve as President for these past 2 years. I look forward to working with all of you in making IATSIC an even bigger contributor to care of the injured globally.

\section{Compliance with ethical standards}

Conflict of interest No benefits in any form have been received or will be received from a commercial party related directly or indirectly to the subject of this article. 


\section{References}

1. World Bank (2016) http://data.worldbank.org. Accessed 5 May 2016

2. World Health Organization (2016) WHO Global Health Estimates 2012. http://www.who.int/healthinfo/global_burden_dis ease/estimates/en/index 1.html. Accessed 5 May 2016

3. International Association for Trauma Surgery and Intensive Care (IATSIC) (2016) http://www.iatsic.org/. Accessed 6 May 2016

4. Mock CM, Nguyen S, Quansah R, Arreola-Risa C, Viradia R, Joshipura M (2006) Evaluation of trauma care capabilities in four countries using the WHO-IATSIC guidelines for essential trauma care. World J Surg 30:946-956

5. World Health Organization (2004) Guidelines for essential trauma care. World Health Organization, Geneva

6. World Health Organization (2005) Prehospital trauma care systems. World Health Organization, Geneva

7. World Health Organization (2009) Guidelines for trauma quality improvement programmes. World Health Organization, Geneva

8. American College of Surgeons (2014) Resources for optimal care of the injured patient. American College of Surgeons, Chicago
9. LaGrone L, Riggle K, Joshipura M, Quansah R, Reynolds T, Sherr K et al (2016) A systematic review of global utilization of the world health organization's trauma care guidelines. Bull WHO 94:585-598. http://www.who.int/bulletin/volumes/94/8/ 15-162214.pdf. Accessed 20 Aug 2016

10. El Sayed MJ, Bayram JD (2013) Prehospital emergency medical services in Lebanon: overview and prospects. Prehosp Disaster Med 28:163-165

11. PanAmerican Trauma Society (2016) http://www.panamtrauma. org/page-1854408. Accessed 5 May 2016

12. O'Reilly G (2013) Implementation of the trauma quality improvement programmes as part of an educational intervention at Yangon general hospital in Myanmar. Alfred Emergency and Trauma Centre, Melbourne

13. Mock C, Abantanga F, Goosen J, Joshipura M, Juillard C (2009) Strengthening care of injured children globally. Bull WHO 87:382-389

14. Neira J (2011) Categorization of trauma care centres in the Republic of Argentina. Basis for implementation of an institutional program: first intersociety consensus of the CICCATED. Academia Nacional de Medicina, Buenos Aires 